\title{
Feasibility and acceptability of using bronchial hyperresponsiveness to manage asthma in primary care: a pilot study
}

\author{
*James A Turtona, Nicholas J Glasgowa, John D Brannan ${ }^{b}$ \\ ${ }^{a}$ Medical School, Australian National University, Canberra, ACT 2606, Australia \\ ${ }^{\mathrm{b}}$ Department of Respiratory and Sleep Medicine, Royal Prince Alfred Hospital, Camperdown, NSW 2050, Australia
}

Original submission 15th November 2010; resubmitted 31st March 2011; revised 21st June 2011; accepted 2nd August 2011; online 21st September 2012

\begin{abstract}
Aims: To determine if indirect testing for bronchial hyperresponsiveness (BHR) to monitor inhaled corticosteroid (ICS) treatment in asthma is feasible and acceptable in primary care.

Methods: Fourteen adult patients with asthma aged 22-70 years (4M:10F, forced expiratory volume in $1 \mathrm{~s}>70 \%$ predicted) taking ICS performed a test for BHR using mannitol on three visits 6 weeks apart. ICS dose adjustments were made based on the presence of BHR. The Asthma Quality of Life Questionnaire (AQLQ) and the Asthma Control Questionnaire were used at each visit. A semi structured interview at study exit assessed subject acceptability.

Results: BHR did not return in those with no BHR at study entry $(n=9)$ with decreasing ICS dose. Improvements in BHR with increasing ICS dose $(n=5)$ were observed with clinically significant improvements in AQLQ (mean score increase $>0.5, p=0.02$ ). Feasibility and acceptability of BHR testing was demonstrated.

Conclusions: It is feasible and acceptable to perform BHR testing using mannitol to help identify patients with asthma who would benefit from ICS dose increases and those with no BHR who could have a dose reduction.

Trial Registration: Australia New Zealand Clinical Trial Registry ACTRN12610000807055

(C) 2012 Primary Care Respiratory Society UK. All rights reserved.

JA Turton et al. Prim Care Respir J 2012; 21(1): 28-34

http://dx.doi.org/10.4104/pcrj.2011.00079
\end{abstract}

Keywords asthma control, bronchial hyperresponsiveness, inhaled corticosteroids, treatment, mannitol, primary care

\section{See linked editorial by Beilby on pg 4}

\section{Introduction}

Asthma is a chronic inflammatory disease that is commonly managed in primary care clinics. Asthma symptoms and lung function are not always effective at predicting the benefits of inhaled corticosteroids (ICS), 1,2 and this may explain the significant morbidity seen in the presence of management guidelines..$^{2-4}$ All clinicians are currently faced with the challenge of determining asthma severity and control without an accepted reliable indicator of treatment effectiveness. ${ }^{5}$ There have been calls for changes in asthma management $t^{6,7}$ and suggestions of systematic monitoring of disease activity using objective patient- orientated measures. ${ }^{5}$ Considering that there are no new asthma treatments in the pipeline that are superior to ICS, more effective ways of using ICS in primary care are now needed.

The two key pathophysiological features of asthma are bronchial hyperresponsiveness (BHR) and inflammation. ${ }^{8}$ These often persist beyond initial improvements in symptoms and lung function. ${ }^{9}$ Tests for BHR have had practical limitations in primary care; however, a safe and effective point-of-care test using inhaled mannitol is now available. ${ }^{10,11}$ BHR to mannitol results from the release of endogenous mediators (e.g. histamine, leukotrienes, prostaglandins) from resident inflammatory cells that are sensitive to ICS such as mast cells and eosinophils. 12,13 Mannitol provocation testing has demonstrated potential in

\footnotetext{
* Corresponding author: Dr James A Turton, Australian National University, School of General Practice, Rural and Indigenous Health, Level 2, Bldg 4, The Canberra Hospital PO Box 11 Woden, Canberra, Australian Capital Territory 2606, Australia. E-mail: james.turton@anu.edu.au
} 
monitoring both the introduction ${ }^{14,15}$ and withdrawal of ICS. ${ }^{16}$

We performed a pilot study in primary care to assess the feasibility and acceptability of using inhaled mannitol to manage asthma with ICS. We also wanted to explore whether measuring BHR could help with making decisions on reducing or increasing ICS dose in a primary care population of asthma patients.

\section{Methods}

\section{Subjects}

Subjects were recruited from a primary care practice in Canberra, Australia over a 30-week period in 2008-2009. An invitation was mailed to all adults attending the practice aged $18-70$ years with a clinical diagnosis of asthma who had been prescribed any form of ICS within the previous year. Subjects were excluded if there was a diagnosis of any other lung disease or if they had been unwell in the 4 weeks prior to joining the study. Ex-smokers with $a<10$ pack-year history and no smoking in the previous 6 months were eligible; current smokers were excluded. Subjects were required to have a forced expiratory volume in 1 second $\left(\mathrm{FEV}_{1}\right)$ of $>70 \%$ predicted.

\section{Study design}

The study used an open single-arm prospective observational design. Eligible subjects had a mannitol challenge test performed at baseline. The decision to increase, decrease, or maintain ICS or long-acting $\beta_{2}$-agonist (LABA) according to the presence of BHR was made by the primary care physician. If BHR was present, the dose of ICS was increased. If there was no BHR, the dose of ICS was decreased. Subjects with no BHR taking combination ICS and LABA with normal lung function had their LABA replaced with a short-acting $\beta_{2}$-agonist (SABA) as required. They were invited to state a goal for their asthma treatment and were encouraged to be adherent to twice daily dosing with ICS in order to achieve this goal. Subjects returned to the primary care practice for two further visits each 6 weeks apart for repeat mannitol challenge testing and ICS dose adjustment. They were able to return for an unscheduled visit at any time in the 12 weeks of the study if they experienced an exacerbation of respiratory symptoms. All visits were performed by a primary care physician (lead author) trained in spirometry and bronchial provocation challenge testing.

\section{Spirometry}

Spirometry was performed at all visits according to the American Thoracic Society criteria using NHANES III predicted values ${ }^{17}$ on a MicroLab ${ }^{\text {TM }}$ ML3500 spirometer (Micromedical, UK) which underwent a daily calibration check with a $3 \mathrm{~L}$ syringe.

\section{Mannitol challenge}

Inhaled mannitol was delivered using a commercial preparation (AridolTM, Pharmaxis Ltd, Frenchs Forest, NSW, Australia) which currently has regulatory approval in the USA, the European Union, South Korea and Australia for the assessment of BHR to assist in asthma diagnosis. Prior to testing, subjects were asked to withhold SABA for 8 hrs, ICS for 12 hrs and ICS/LABA combinations for $24 \mathrm{hrs}$. Increasing doses of mannitol $(0,5,10$,
$20,40,80,160,160,160 \mathrm{mg}$ ) were inhaled via a dry powder inhaler until either a total cumulative dose of $635 \mathrm{mg}$ was administered or a $15 \%$ fall in $\mathrm{FEV}_{1}$ from baseline was observed 60 $\mathrm{s}$ after dosing. ${ }^{10}$ Airway sensitivity is expressed as the cumulative provoking dose of mannitol to cause a $15 \%$ fall in $\mathrm{FEV}_{1}\left(\mathrm{PD}_{15}\right)$.

All visits took place in a standard primary care clinical consultation room and required no more facilities than a portable spirometer, salbutamol (pressurised metered dose inhaler (pMDI) and spacer), a stopwatch and a hand calculator. Oxygen and the facilities to administer nebulised inhaled $\beta_{2}$-agonist were located in an adjacent room of the practice.

\section{Inhaled corticosteroid adherence monitoring}

Subjects taking ICS using pMDIs were issued with the Smartinhaler TM monitoring device (Nexus6 Ltd, Auckland, New Zealand). The Smartinhaler' ${ }^{\mathrm{TM}}$ recorded the time and date of each pMDI actuation. There was no covert monitoring as subjects were fully informed of the nature of this device. Those subjects taking ICS via a dry powder inhaler could not be monitored for adherence using the Smartinhaler ${ }^{\mathrm{TM}}$ device.

\section{Questionnaires}

The Asthma Quality of Life Questionnaire (AQLQ) ${ }^{18}$ and the Asthma Control Questionnaire (ACQ) $)^{19,20}$ were administered at each visit. An additional questionnaire to assess acceptability of the mannitol challenge test was also used. Subjects were asked to rank on a score of 1-5 (with 5 the most favourable score) how rapid and easy the test was, how safe and comfortable they felt during the procedure, and if they would perform the test again. Each subject participated in a semi structured interview at the final visit and was asked the following three questions by the investigator:

(1) "What do you feel about having your asthma monitored using this process?"

(2) "How do you think that having a personalised goal for your treatment has improved your asthma?"

(3) "Do you think that the SmartinhalerтM device had any impact on your asthma management?"

The responses were hand recorded and analysed for themes.

\section{Statistics}

The provoking dose of mannitol ( $\left.\mathrm{PD}_{15}\right)$ is calculated from the linear interpolation of the dose $(\mathrm{mg})$ response (\% fall in $\mathrm{FEV}_{1}$ ) curve. If no sensitivity to mannitol was recorded, this was assigned a PD15 of $680 \mathrm{mg}$ for statistical purposes. Where possible, Student paired t-tests were performed on normally distributed data. Unless otherwise stated, data are expressed as mean \pm standard deviation (SD).

\section{Ethics}

Ethical approval was obtained from the Human Research Ethics Committees of the Australian National University (2008/497) and Australian Capital Territory Health (ETH.8/08.759). All subjects gave informed consent prior to participation in the study.

\section{Results}

One hundred and forty-seven patients were identified from the 
primary care clinic's electronic database. Twenty-seven (18\%) responded with $21(14 \%)$ meeting the study eligibility criteria. Of the 21 screened subjects, seven (33.3\%) were ineligible due to abnormal spirometry with a mean $\mathrm{FEV}_{1} 58 \%$ (range $40-69 \%$ ) of the predicted value. The baseline demographic characteristics of the subjects are summarised in Table 1

The acceptability of the challenge procedure was high with the pooled median responses for speed, ease, safety, comfort, and overall rating being scored 4 out of 5 for all visits. All subjects indicated that they would be prepared to undertake a

Table 1. Demographics

\begin{tabular}{|c|c|c|c|c|c|c|c|c|c|c|}
\hline $\begin{array}{l}\text { Subject } \\
\text { No. }\end{array}$ & $\begin{array}{l}\text { Age } \\
\text { (yrs) }\end{array}$ & Sex & $\begin{array}{l}\text { BMI } \\
\left(\mathrm{kg} / \mathrm{m}^{2}\right) \\
\text { (yrs) }\end{array}$ & $\begin{array}{l}\text { Age of } \\
\text { diagnosis }\end{array}$ & $\begin{array}{l}\text { GINA } \\
\text { class } \\
\text { Pred }\end{array}$ & $\begin{array}{l}\text { Baseline } \\
\mathrm{FEV}_{1} \%\end{array}$ & $\begin{array}{l}\text { Baseline } \\
\text { FEV }_{1} / \text { FVC }\end{array}$ & $\begin{array}{l}\text { Asthma } \\
\text { medication } \\
(\mu \mathrm{g} / \text { day })\end{array}$ & $\begin{array}{l}\text { Inhaled } \\
\text { dose } \\
\text { (mg) }\end{array}$ & $\begin{array}{l}\text { Mannitol } \\
\text { PD15 }\end{array}$ \\
\hline 1 & 38 & $\mathrm{~F}$ & 22.6 & 20 & 3 & 86.0 & 86.3 & FLU/Sm & $1000 / 200$ & 265 \\
\hline 2 & 48 & $\mathrm{~F}$ & 22.8 & 20 & 1 & 83.9 & 76.0 & $\mathrm{FLU} / \mathrm{Sm}$ & $500 / 100$ & 458 \\
\hline 3 & 64 & $\mathrm{~F}$ & 19.5 & 58 & 2 & 71.9 & 77.8 & BUD/Ef & $200 / 6$ & No $P_{15}$ \\
\hline $4^{*}$ & 45 & $\mathrm{M}$ & 28.0 & 44 & 1 & 118.4 & 85.5 & BUD/Ef & $800 / 24$ & No $P_{15}$ \\
\hline 5 & 70 & $\mathrm{~F}$ & 29.9 & 68 & 3 & 71.5 & 75.7 & BUD/Ef & $800 / 24$ & No $\mathrm{PD}_{15}$ \\
\hline 6 & 22 & $\mathrm{~F}$ & 26.2 & 4 & 2 & 97.9 & 82.4 & $\mathrm{FLU} / \mathrm{Sm}$ & $1000 / 100$ & No $P_{15}$ \\
\hline 7 & 69 & $\mathrm{M}$ & 32.7 & 55 & 3 & 71.5 & 68.1 & BUD/Ef & $400 / 12$ & No $P_{15}$ \\
\hline 8 & 36 & $\mathrm{~F}$ & 26.9 & 34 & 2 & 90.1 & 84.0 & BUD & 400 & No $\mathrm{PD}_{15}$ \\
\hline 9 & 55 & $\mathrm{M}$ & 29.0 & 30 & 2 & 79.9 & 68.9 & FLU & 500 & 47 \\
\hline 10 & 64 & $\mathrm{~F}$ & 24.9 & 53 & 2 & 95.3 & 83.6 & BUD/Ef & $800 / 24$ & 381 \\
\hline 11 & 62 & $\mathrm{~F}$ & 36.0 & 42 & 2 & 83.7 & 86.6 & BUD/Ef & $800 / 24$ & No $P_{15}$ \\
\hline 12 & 62 & $\mathrm{~F}$ & 23.6 & 33 & 2 & 79.9 & 72.9 & BUD/Ef & $400 / 12$ & No $P_{15}$ \\
\hline 13 & 40 & $\mathrm{M}$ & 20.2 & 5 & 2 & 93.7 & 73.4 & $\mathrm{FLU} / \mathrm{Sm}$ & $500 / 50$ & 544 \\
\hline 14 & 60 & $\mathrm{~F}$ & 25.9 & 59 & 1 & 97.1 & 89.7 & $\mathrm{BEC}$ & 100 & No $\mathrm{PD}_{15}$ \\
\hline Mean & 55 & $10 \mathrm{~F} / 4 \mathrm{M}$ & 26.3 & 37.5 & & 87.2 & 79.4 & & & $259.7 * *$ \\
\hline Range & $22-70$ & & $19.5-36$ & $4-68$ & & 71.5-118.4 & 68.1-89.7 & & & \\
\hline
\end{tabular}

\section{Table 2. Qualitative analysis of semi structured interview at study exit}

\section{Theme \\ Exemplar}

What do you feel about having your asthma monitored using this process?

\begin{tabular}{|c|c|}
\hline Chronic disease insight & "When well previously I thought (my asthma) was cured - now I know I should be taking (ICS) all the time" \\
\hline \multirow[t]{3}{*}{ Objective nature of the management process } & "I like to know the measurement" \\
\hline & "(the process) helps measure (the) effect of medication" \\
\hline & "(ICS) dose adjustments make sense" \\
\hline \multirow[t]{3}{*}{ Comparison with usual standard of asthma care } & "Follow-up using measurement was better" \\
\hline & "Better process than just seeing the doctor for 10 minutes" \\
\hline & "Good because one visit is a stab in the dark assessment" \\
\hline \multicolumn{2}{|c|}{ How do you think that having a personalised goal for your treatment has improved your asthma?* } \\
\hline \multirow[t]{3}{*}{ Therapeutic alliance } & "(a) goal focuses (my) efforts" \\
\hline & "(it was) helpful for the doctor to know my goal" \\
\hline & "It was easier for the (doctor) to understand my motivations" \\
\hline \multirow[t]{2}{*}{ Insight } & $\begin{array}{l}\text { "I didn't really understand what the goal was about initially - after some time it made more sense } \\
\text { as I got to understand the process" }\end{array}$ \\
\hline & "(in the past) I treated symptoms without (a) long term view" \\
\hline \multicolumn{2}{|c|}{ Do you think that the Smartinhaler ${ }^{\mathrm{TM}}$ device had any impact on your asthma management? } \\
\hline \multirow[t]{2}{*}{ Electronic surveillance } & "Knowing that it was recording dosing time made me more conscious of taking (my) medicine" \\
\hline & "Knowing someone is going to check the (dosing) times makes you comply" \\
\hline
\end{tabular}




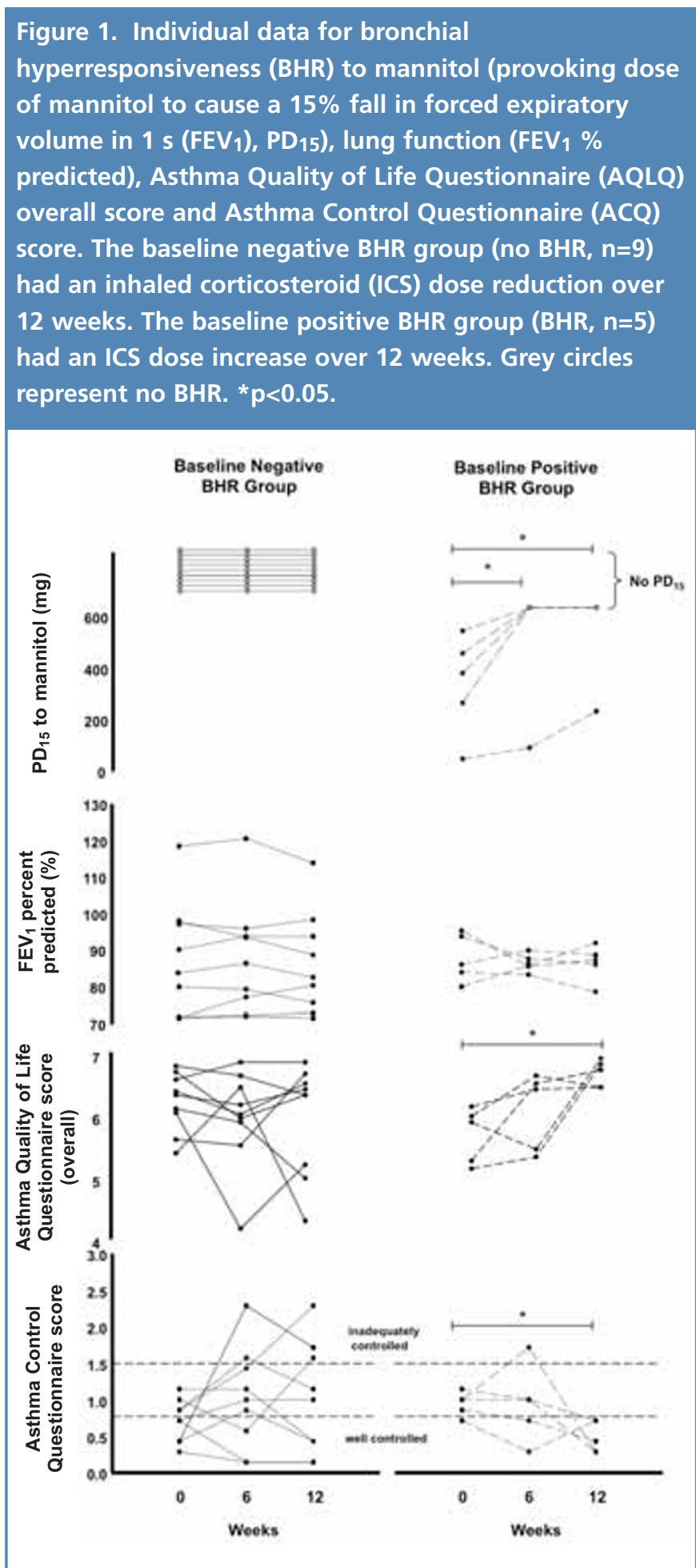

mannitol challenge at a future time if needed. The qualitative analysis of the semi structured interview shows the subjects' views of asthma monitoring, goal setting, and electronic adherence monitoring of ICS use (Table 2).

All subjects performed spirometry and the mannitol challenge test per protocol. No subject withdrew from the study. There were no serious adverse events and all of those reported
Figure 2. Mean and standard error of the doses of inhaled corticosteroid (fluticasone equivalents $=\mu \mathrm{g}$ ) and long-acting $\beta_{2}$-agonist (pooled doses $=\mu \mathrm{g}$ ) at each study visit over 12 weeks for subjects without bronchial

hyperresponsiveness (BHR) to mannitol $(n=9)$ and those with BHR $(n=5)$ at the beginning of the study. ${ }^{*} p<0.05$, **p<0.01,***p<0.001.

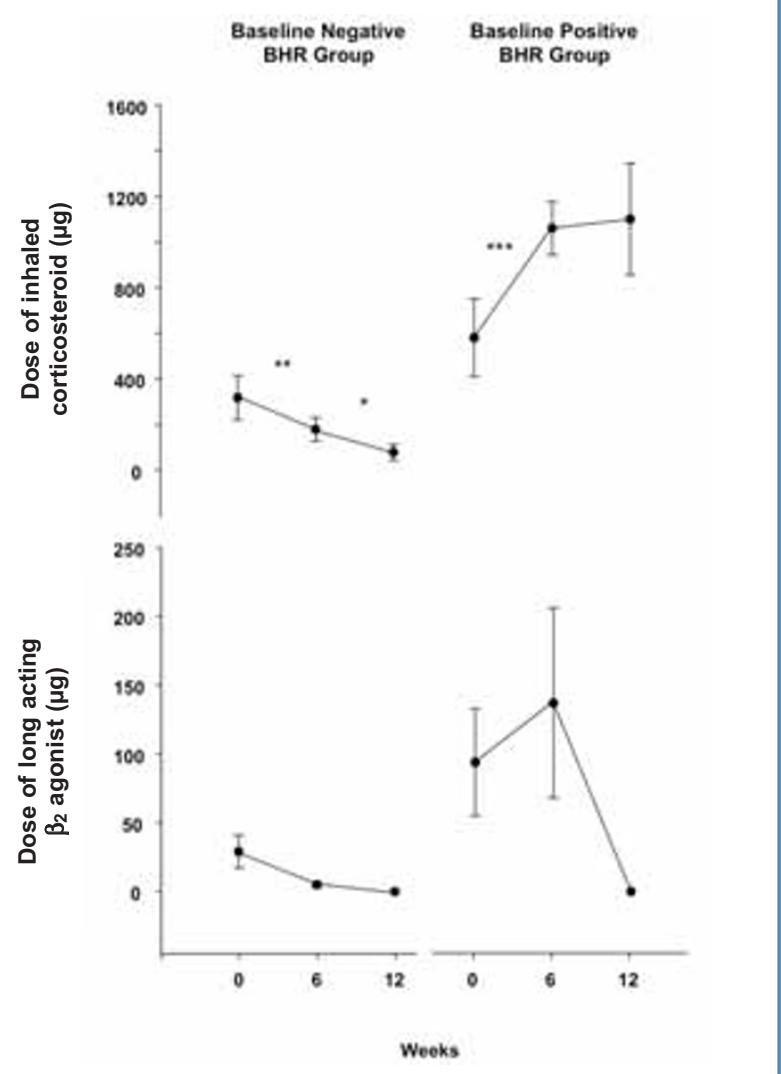

were minor. Only one subject had an unscheduled visit for increased respiratory symptoms that resolved rapidly (Table 1 , subject 7). The mean time of the challenge tests was 19 min (range 9-24).

Of the 14 enrolled subjects who proceeded to a mannitol challenge at the first visit, nine had no BHR while five demonstrated BHR (Table 1 and Figure 1). All subjects with no BHR at the initial visit maintained no BHR throughout the study despite a significant decrease in ICS dose and withdrawal of LABA (Figure 2). This dose reduction resulted in no significant changes in mean AQLQ and ACQ scores (Figure 1). Three subjects in the no BHR group had ACQ scores in the inadequately controlled asthma range at week 12 . For these subjects the percentage fall in $\mathrm{FEV}_{1}$ (after a cumulative mannitol dose of $635 \mathrm{mg}$ ) was $0 \%, 3.5 \%$ and $6.4 \%$, respectively. Four subjects with mild BHR to mannitol (PD $15>155 \mathrm{mg}$ ) had no BHR following a significant increase in ICS dose after 6 weeks (Figure 1). The subject with the most severe BHR (Table 1, subject 9, $\mathrm{PD}_{15}=47 \mathrm{mg}$ ) improved over 12 weeks to the mild range. The 


\begin{tabular}{|c|c|c|c|}
\hline \multirow{2}{*}{$\begin{array}{l}\text { Subject } \\
\text { no. }\end{array}$} & \multirow{2}{*}{$\begin{array}{l}\text { Baseline } \\
\text { BHR }\end{array}$} & \multicolumn{2}{|c|}{ Average measured adherence (\%) } \\
\hline & & $0-6$ weeks & $6-12$ weeks \\
\hline 1 & BHR & 99 & 100 \\
\hline 2 & $\mathrm{BHR}$ & $(D F)^{*}$ & 82 \\
\hline 5 & No BHR & $(\mathrm{DPl})^{\star}$ & 45 \\
\hline 6 & No BHR & 100 & $(D F)^{\star}$ \\
\hline 8 & No BHR & 88 & (ICS withdrawn)* \\
\hline 9 & $\mathrm{BHR}$ & 82 & 93 \\
\hline 10 & BHR & $(\mathrm{DPl})^{\star}$ & 95 \\
\hline 11 & No BHR & 68 & 32 \\
\hline 12 & No BHR & 93 & 96 \\
\hline 13 & $\mathrm{BHR}$ & 91 & 92 \\
\hline Mean & & 89 & 79 \\
\hline SD & & 11 & 26 \\
\hline
\end{tabular}

reduction in $\mathrm{PD}_{15}$ in the $\mathrm{BHR}$ baseline positive group was statistically significant $(p<0.05)$ at 6 and 12 weeks (Figure 1$)$. This corresponded with a statistically significant improvement in both AQLQ and ACQ over 12 weeks (Figure 1). There was also a clinically significant improvement ( $>0.5$ increase in mean score) in the overall AQLQ scores as well as in the symptoms and activity limitation domains. There were no significant changes in the mean FEV $V_{1}$ from baseline to week 12 in those who had BHR or no BHR (Figure 1).

Adherence to ICS therapy was observed to be an average of $84 \%$ (range $45-100 \%$ ) for the 12 weeks of the study in the subgroup of subjects using a pMDI $(n=10)$ (Table 3 ). Those with BHR at baseline $(n=5)$ were observed to maintain a high degree of adherence over 6-12 weeks (92\%, range $82-100 \%$ ). Monitoring data for two subjects were lost due to data upload failures of the SmartinhalerTM device (subjects 2 and 6). One subject (subject 8) had adherence data for ICS use in the first 6week treatment period but not for the second 6 -week treatment period as ICS was withdrawn.

\section{Discussion}

This study demonstrated that BHR testing using inhaled mannitol was feasible and acceptable in the primary care setting. This supports the findings of two large phase 3 studies ${ }^{10,11}$ that demonstrated safety and efficacy of the mannitol challenge in tertiary care. Furthermore, despite the small numbers, we identified clinically significant improvements in AQLQ associated with 'well controlled' ACQ scores. These changes correlated with improvements in BHR after ICS dose increases. The AQLQ is validated to measure the effect of asthma therapies on symptoms, and other studies have needed much larger numbers of subjects to show such improvement. ${ }^{21}$ This finding is consistent with studies that have shown clinical improvements with ICS over weeks to months in association

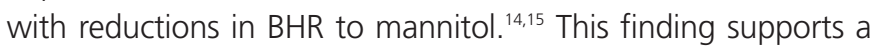
hypothesis that no response to mannitol may be a marker of asthma control. ${ }^{15,22}$ We also successfully reduced ICS in subjects with no BHR with no deterioration in AQLQ scores in the majority of subjects, and no change in lung function.

We were able to perform challenge testing using the resources that are commonly found in primary care clinics. The time to perform the mannitol challenge test in this pilot study was in keeping with the times observed in tertiary care settings. ${ }^{10,11}$ The study clinician performed all the spirometry and challenge tests throughout this pilot study, in contrast to the likely normal practice in primary care clinics. We do not anticipate that busy primary care clinicians would perform these measurements themselves but foresee that primary care nurses, physician assistants or respiratory therapists might embrace such a role. Mannitol challenge testing by allied health staff may thus be integrated into a platform of asthma education.

A qualitative analysis of the semi structured interviews at the final visit found themes of an increased understanding of the chronic nature of asthma and an understanding of the value of objectively measuring asthma control. Subjects considered that this monitoring process was better than past experiences of primary care asthma management. Personalised asthma treatment goals were valued, as was the process of goal setting between doctor and patient. We restricted the thematic analysis related to goal setting to those subjects who were BHR positive at study entry as these were the ones who had an objective improvement in their asthma. Future studies should address the issue of goal setting for all subjects (BHR positive and negative) in an open-ended manner. We propose that this process of BHR monitoring has the capacity to both raise and meet the expectations for better primary care asthma management in both clinicians and patients.

While the subject retention in this pilot study was high, we would like to have recruited more patients with asthma overall. The low response rate to mailed invitations (18\%) was disappointing although not uncommon in primary care research. ${ }^{23}$ We feel that our study is representative of the usual way in which primary care clinics recall patients for treatment. However, despite the small numbers, the results of this pilot study are in agreement with studies in larger populations. ${ }^{14-16} \mathrm{~A}$ cause for concern is that one-third of screened subjects had poor lung function ( $F E V_{1}<70 \%$ ) and failed to meet the eligibility criteria for BHR testing. This observation is supported by studies in primary care showing that many subjects have poor asthma control, and highlights the need for spirometry testing in chronic respiratory disease as an urgent continuing priority. ${ }^{3}$ For patients with asthma with poor lung function, it is possible that they may be eligible for BHR monitoring once lung function has improved with ICS therapy.

Primary care asthma populations are a heterogeneous group of patients with predominantly mild to moderate asthma. 
Overdiagnosis of asthma in primary care may be up to $30 \%,{ }^{24}$ and in this pilot study we may have attracted subjects wanting confirmation of their diagnosis. We did observe that some subjects had increases in AQLQ and ACQ severity scores in the presence of ICS withdrawal with no BHR. These subjects showed percentage falls in $\mathrm{FEV}_{1}$ that are comparable to nonasthma patients without airway reactivity. ${ }^{10,11}$ Such subjects may require further clinical investigation. Using this study design we were able to select out subjects who would benefit from an increase in ICS dose and also identified subjects in whom a decrease in dose could be made. The absence of BHR to stimuli such as mannitol or exercise in asthma patients who take ICS suggests that the optimal dose of ICS has been reached. ${ }^{15,22}$ We were able to withdraw LABA in patients both with and without BHR at 12 weeks. Larger studies are warranted to determine if LABA can be removed in subjects who are otherwise well controlled and have no BHR.

It has been shown that primary care clinicians are less likely to decrease the dose of ICS than their counterparts in tertiary care. ${ }^{25}$ This may be because asthma symptoms and lung function are the only readily accessible markers of disease activity in primary care. In this pilot study, symptoms and lung function at baseline would not have been sufficient on their own to make a decision on down-titrating ICS doses or withdrawing LABA.

This study featured an electronic dose adherence monitor for pMDI-delivered ICS. Adherence to ICS is often poor (50\%) and is related to poor asthma outcomes. ${ }^{26}$ In contrast, we observed high levels of sustained adherence $(>80 \%)$ to 12 weeks, predominantly in those whom we identified as having BHR. This finding may be due to a combination of the awareness of the dose monitors as well as the process of goal setting and encouragement by the study clinician. We did not measure adherence during a run in period and future studies may address this issue.

\section{Conclusions}

We have demonstrated that it is feasible to perform a test for BHR in primary care. The test was safe and acceptable. Monitoring asthma using this test has the potential to improve asthma control as well as lowering ICS doses. While the subject numbers were small, clinically meaningful outcomes were observed based on titrating ICS dose according to BHR. Larger studies in primary care are now warranted.

\section{Handling editor Chris Griffiths Statistical review Gopal Netuveli}

Acknowledgements The authors wish to acknowledge the support of Professor Marjan Kljakovic and the Primary Health Care Research, Evaluation and Development (PCHRED) program at the Australian National University in ensuring that this study could be completed successfully. They would like to thank Professor Juniper for her permission to use the AQLQ and ACQ questionnaires. Pharmaxis Ltd provided Aridol ${ }^{\mathrm{TM}}$ test kits and the temporary loan of a spirometer. GSK Ltd provided some Ventolin ${ }^{\mathrm{TM}}$ inhalers and Volumatic ${ }^{\mathrm{TM}}$ spacer devices to support the study. Neither Pharmaxis Ltd nor GSK Ltd were involved in the study design, collection, interpretation of data, or production of this paper.
Conflicts of interest JAT holds shares in Pharmaxis Ltd. NJG has no conflict of interest. JDB receives royalties from the sale of Arido ${ }^{\mathrm{TM}} / \mathrm{O}$ smohale $\mathrm{e}^{\mathrm{TM}}$, holds shares in Pharmaxis Ltd, and has acted as a consultant to Pharmaxis Ltd.

Contributorship JAT and JDB have access to the data and take responsibility for the integrity of the data and accuracy of the data analysis. JAT contributed to the design, implementation, interpretation, analysis and writing. JDB contributed to the design, interpretation, analysis and writing. NJG contributed to the design, interpretation and writing.

Funding An Australian General Practice Education \& Training (GPET) Registrar Research Fund Grant supported this work.

\section{References}

1. Rosi E, Ronchi MC, Grazzini M, Duranti R, Scano G. Sputum analysis, bronchial hyperresponsiveness, and airway function in asthma: results of a factor analysis. $J$ Allergy Clin Immunol 1999;103(2 Pt 1):232-7. http://dx.doi.org/10.1016/S00916749(99)70496-3

2. Sont JK, Han J, van Krieken JM, et al. Relationship between the inflammatory infiltrate in bronchial biopsy specimens and clinical severity of asthma in patients treated with inhaled steroids. Thorax 1996;51(5):496-502. http://dx.doi.org/10.1136/thx.51.5.496

3. Chapman KR, Boulet LP, Rea RM, Franssen E. Suboptimal asthma control: prevalence, detection and consequences in general practice. Eur Respir J 2008;31(2):320-5 http://dx.doi.org/10.1183/09031936.00039707

4. Rabe KF, Adachi M, Lai CK, et al. Worldwide severity and control of asthma in children and adults: the global asthma insights and reality surveys. J Allergy Clin Immunol 2004;114(1):40-7. http://dx.doi.org/10.1016/j.jaci.2004.04.042

5. Horne R, Price D, Cleland J, et al. Can asthma control be improved by understanding the patient's perspective? BMC Pulm Med 2007; 7:8. http://dx.doi.org/10.1186/1471-2466-7-8

6. Ruffin RE. Time to rethink asthma management. Thorax 2009;64(12):1013-14. http://dx.doi.org/10.1136/thx.2009.124040

7. Hancox RJ, Le Souef PN, Anderson GP, Reddel HK, Chang AB, Beasley R. Asthma: time to confront some inconvenient truths. Respirology 2010;15(2):194-201. http://dx.doi.org/10.1111/j.1440-1843.2009.01700.x

8. Global Initiative for Asthma. Revised 2007. Global strategy for asthma management and prevention. National Institutes of Health, Lung and Blood Institute. NHLBIWHO Workshop Report. Medical Communication Resources Inc, Bethesda, Maryland. pp 16-19. Available from: http://www.ginasthma.org

9. Reddel HK, Taylor DR, Bateman ED, et al. An official American Thoracic Society/European Respiratory Society statement: asthma control and exacerbations: standardizing endpoints for clinical asthma trials and clinical practice. Am J Respir Crit Care Med 2009;180(1):59-99. http://dx.doi.org/10.1164/rccm.200801-060ST

10. Brannan JD, Anderson SD, Perry CP, Freed-Martens R, Lassig AR, Charlton B. The safety and efficacy of inhaled dry powder mannitol as a bronchial provocation test for airway hyperresponsiveness: a phase 3 comparison study with hypertonic $(4.5 \%)$ saline. Respir Res 2005;6:144

11. Anderson SD, Charlton B, Weiler JM, et al. Comparison of mannitol and methacholine to predict exercise-induced bronchoconstriction and a clinical diagnosis of asthma. Respir Res 2009;10:4

12. Brannan JD, Gulliksson M, Anderson SD, Chew N, Seale JP, Kumlin M. Inhibition of mast cell PGD2 release protects against mannitol-induced airway narrowing. Eur Respir J 2006;27(5):944-50

13. Porsbjerg C, Brannan JD, Anderson SD, Backer V. Relationship between airway responsiveness to mannitol and to methacholine and markers of airway inflammation, peak flow variability and quality of life in asthma patients.Clin Exp Allergy 2008;38(1):43-50. http://dx.doi.org/10.1111/j.1365-2222.2007.02878.x

14. Brannan JD, Koskela H, Anderson SD, Chan H-K. Budesonide reduces sensitivity and reactivity to inhaled mannitol in asthmatic subjects. Respirology 2002;7(1):37-44. http://dx.doi.org/10.1046/j.1440-1843.2002.00357.x

15. Koskela H, Hyvärinen L, Brannan JD, Chan H-K, Anderson SD. Sensitivity and validity of three bronchial provocation tests to demonstrate the effect of inhaled corticosteroids in asthma. Chest 2003;124(4):1341-9. http://dx.doi.org/10.1378/chest.124.4.1341

16. Leuppi JD, Salome CM, Jenkins $C R$, et al. Predictive markers of asthma exacerbations during stepwise dose reduction of inhaled corticosteroids. Am J Respir Crit Care Med 2001;163(2):406-12 
17. Hankinson JL, Odencrantz JR, Fedan KB. Spirometric reference values from a sample of the general U.S. population. Am J Respir Crit Care Med 1999;159(1):179-87.

18. Juniper EF, Guyatt GH, Epstein RS, Ferrie PJ, Jaeschke R, Hiller TK. Evaluation of impairment of health related quality of life in asthma: development of a questionnaire for use in clinical trials. Thorax 1992;47(2):76-83. http://dx.doi.org/10.1136/thx.47.2.76

19. Juniper EF, O'Byrne PM, Guyatt GH, Ferrie PJ, King DR. Development and validation of a questionnaire to measure asthma control. Eur Respir J 1999;14(4):902-07. http://dx.doi.org/10.1034/j.1399-3003.1999.14d29.x

20. Juniper EF, Bousquet J, Abetz L, Bateman ED. Identifying 'well-controlled' and 'not well-controlled' asthma using the Asthma Control Questionnaire. Respir Med 2006;100(4):616-21. http://dx.doi.org/10.1016/j.rmed.2005.08.012

21. Juniper EF, Svensson K, O'Byrne PM, et al. Asthma quality of life during 1 year of treatment with budesonide with or without formoterol. Eur Respir J 1999;14(5):1038-43. http://dx.doi.org/10.1183/09031936.99.14510389
22. Brannan JD. Bronchial hyperresponsiveness in the assessment of asthma control. Airway hyperresponsiveness in asthma: its measurement and clinical significance. Chest 2010;138(2 Suppl):11S-7S. http://dx.doi.org/10.1378/chest.10-0231

23. Veitch C, Hollins J, Worley P, Mitchell G. General practice research. Problems and solutions in participant recruitment and retention. Aust Fam Physician 2001;30(4):399-406

24. Aaron SD, Vandemheen $\mathrm{KL}$, Boulet $\mathrm{LP}$, et al. Overdiagnosis of asthma in obese and nonobese adults. CMAJ 2008;179(11):1121-31. http://dx.doi.org/10.1503/cmaj.081332

25. Diette GB, Patino CM, Merriman B, et al. Patient factors that physicians use to assign asthma treatment. Arch Intern Med 2007;167(13):1360-6 http://dx.doi.org/10.1001/archinte.167.13.1360

26. Williams LK, Pladevall $M, X i H$, et al. Relationship between adherence to inhaled corticosteroids and poor outcomes among adults with asthma. J Allergy Clin Immuno/ 2004;114(6):1288-93. http://dx.doi.org/10.1016/j.jaci.2004.09.028

\section{Available online at http://ww w.thepcrj.org}

